\title{
The Other Side of Here and Now: Cross-Cultural Reflections on the Politics of Improvisation Studies
}

\section{Scott Currie}

Ethnomusicologists who view the Improvisation, Community, and Social Practice [ICASP] paradigm as one of the most significant developments in recent years, insofar as it brings new perspectives and approaches to bear upon one of the perennial concerns of our discipline, may nonetheless feel some discomfort with the persistently unmarked use of the term "improvisation." This may be the case particularly in cross-cultural contexts where its universalizing connotations might tend-however inadvertently_to efface significant differences among the many diverse forms of improvisational practice encountered worldwide. ${ }^{1}$ In critically engaging from a global standpoint the fundamental premises of ICASP, this essay will consider some of the issues involved in broadening the scope of improvisation studies beyond the cluster of North American and European traditions-variously glossed as free or avant-garde jazz and creative, free, or improvised music; hereafter dubbed "transatlantic improvised music"-that have thus far constituted its main focus. ${ }^{2}$ In particular, a focus on the problematics of intercultural collaboration, covering improvisational traditions from Africa to Asia, will call into question the cross-cultural validity of understanding improvisational practices as musical analogues for counter-hegemonic political dialogue and action. ${ }^{3}$ Drawing upon influential studies of non-Western improvisation traditions and my own fieldwork experiences, I will re-examine two performances from the Guelph Jazz Festival—cited as exemplary by leading ICASP researchers-to elucidate how ideological commitments to transcending cultural difference through collaborative improvisation can shape the political meanings of extemporaneous music-making. Ultimately, an ethnographic focus on ritual overdetermination of meaning within festive performance frames can reveal the significance that ICASP organizers' conception of improvisation —as "a crucial model for political, cultural, and ethical dialogue and action"—plays in empowering artists to imagine and realize utopian, transcultural, socio-sonic communities (Heble, "About ICASP").

In the interest of reflexivity, I should note that, while trained in African American, Latin American, and Near Eastern music, I have conducted most of my ethnomusicological field research on contemporary transatlantic improvised music collectives in Berlin and New York City, where many of the ideals and positions ICASP champions resonate strongly among a critical mass of artists. This should come as no great surprise, since the Vision Festival-the locus of my ethnographic engagement in New York for the last two decades-serves as one of ICASP's main exemplars of improvisation as grassroots socio-political activism. The relativistic cross-cultural perspective internalized in my disciplinary training nevertheless leaves me unable to wholeheartedly endorse such statements of progressive position as the following:

\begin{abstract}
Musical improvisation is a crucial model for political, cultural, and ethical dialogue and action. Taking as a point of departure performance practices that cannot readily be scripted, predicted, or compelled into orthodoxy, we argue that the innovative working models of improvisation developed by creative practitioners have helped to promote a dynamic exchange of cultural forms and to encourage new, socially responsive forms of community building across national, cultural, and artistic boundaries. Improvisation, in short, has much to tell us about the ways in which communities based on such forms are politically and materially pertinent to envisioning and sounding alternative ways of knowing and being in the world. Improvisation demands shared responsibility for participation in community, an ability to negotiate differences, and a willingness to accept the challenges of risk and contingency. Furthermore, in an era when diverse peoples and communities of interest struggle to forge historically new forms of affiliation across cultural divides, the participatory and civic virtues of engagement, dialogue, respect, and community-building inculcated through improvisatory practices take on a particular urgency. (Heble, "About ICASP")
\end{abstract}

Since I have in the "The Revolution Never Ended" advanced more limited claims for the specific transatlantic improvised musical practices featured in the Vision Festival, I can stipulate the validity of similar claims for corresponding practices showcased at the Guelph Jazz Festival. As an ethnomusicologist, however, I find the universalizing tone of this passage-engendered by repeated reference to improvisation without any qualification or delimitation-rather problematic due to the troubling politics of its poetics. Many members of my discipline, influenced by Bruno Nettl's pioneering work over the last forty years (see "Thoughts on Improvisation" and "Introduction"), would question whether "improvisation" really means the same thing in different cultures, and might even doubt the applicability of Western notions of improvisation to non-Western traditions with distinct categories and concepts of musical creativity. The diversity of extemporaneous forms worldwide has made it quite difficult for generations of ethnomusicologists to reach any robust consensus on what the "core qualities" of improvisation might be, and certainly militates strongly against any universalistic characterization of improvisation as "at its core and at its best, a democratic, humane, and emancipatory practice" (Heble et al., Fierce Urgency of Now 191). From this disciplinary perspective, insofar as ICASP's foundational axiological understandings of improvisation arise from the cosmopolitan 
transatlantic traditions showcased at the Guelph Jazz Festival, applying them to cases of intercultural collaborationwithout detailed, reflexive attention to the power-relations involved-would run a serious methodological risk of imposing the implicit value structure of a Western ideal-type onto non-Western practices premised upon quite different socio-aesthetic commitments. ${ }^{4}$

\section{Staging "New Communities of Sound": The Politics of Intercultural Collaboration}

In the Fierce Urgency of Now [FUN], written collaboratively by Guelph Jazz Festival artistic director Ajay Heble and fellow ICASP researchers Daniel Fischlin and George Lipsitz, the authors quote at length ethnomusicologist Ingrid Monson's apt cross-cultural caveats from Freedom Sounds. They evince a puzzling disinclination, however, to pursue the implications of the critical questions she asks: "What are the power relations that shape the contact or cultural overlap? Who profits from the contact? Is an area of cultural overlap enforced or voluntary for the participants? .. . Which set of cultural values shapes the process by which divergent cultural elements and practices are shared and synthesized? Which values and ideologies, in other words, are dominant and hegemonic?" (11). Critical ethnographic perspectives of this sort undermine the notion of "free improvisation" as a neutral meeting ground for egalitarian interactions among international artists representing diverse and disparate musical traditions and instead point toward how the tacit conventions of this "non-idiomatic" genre impose upon such encounters aesthetic ideologies of EuroAmerican modernity. From staged separation between actively engaged artists and silent, immobile, passive listeners, to underlying economic relations of wage-labour production and commodified leisure consumption, complex power asymmetries and cultural displacements ensure that such musical exchanges take place upon slippery-sloped terrains and follow courses that cannot but trace the contours inscribed by economic and symbolic capital.

From an ethnomusicological point of view, transatlantic "free improvisation" represents as much of a learned practice-complete with structured conventions and structuring expectations-as any other improvisational tradition. As such, the spaces it opens for intercultural encounter differ from those created by mainstream jazz, rock, folk, funk, or hip-hop mainly in that its characteristic lack of predetermined forms and formulae accommodates a broader range of stylistic differences, even as it imposes certain boundary conditions on the expressive negotiation of those differences, which effectively distinguish preferred modes of collaboration from those associated with other genres. Tendencies to avoid or disrupt steady rhythms, stable key centers, and pre-existing melodic material represent common conventions of negation that set "non-idiomatic," intercultural improvisations apart from "idiomatic," bordercrossing fusions by foreclosing options otherwise conducive to finding common musical ground. ${ }^{5}$

These hallmarks of transatlantic improvised music practice-which privilege invention over variation and innovation over tradition-do not accord with many widely disseminated African improvisational paradigms, such as those documented in John Chernoff's study African Rhythm and African Sensibility, which emphasize repetition (111-12) and discourage "random expression" (122). Furthermore, Eric Charry's fieldwork in Mande Music identifies the salience of such observations to string traditions of the Malian cultural ecumene that foreground variations on accompaniment patterns interrupted by fast melodic flourishes (168). Insofar, then, as intercultural encounters bring representatives of such traditions together with exponents of cosmopolitan jazz and avant-garde music, divergent conventions and conceptualizations provide relatively little common ground between the two normative poles of improvisational praxis.

In fact, in both general principle and specific application, traditional African improvisational concepts and transatlantic "free improvisation" paradigms seem not merely dissonant with one another, but nearly incommensurable, insofar as a key distinguishing characteristic of the latter is avoidance of the very repetition and stability upon which the former is premised. This does not imply that "free" musicians cannot or do not at times incorporate African-diasporic, groovebased improvisation into their performances and repertories, but rather that in so doing they radically shift ensemble dynamics away from the "democratic, egalitarian, and emancipatory" ideals of "non-idiomatic" improvisation and back toward the conventional "idiomatic" roles of leaders and sidemen-with the latter responsible for maintaining a stable, repetitive foundation upon which the former can improvise. Accordingly, from an ethnomusicological standpoint, impromptu improvisational encounters between representatives of these two traditions would appear likely to produce a vacillating juxtaposition of the disparate modes of musical interaction associated with each rather than a unified or unifying fusion. ${ }^{6}$ 


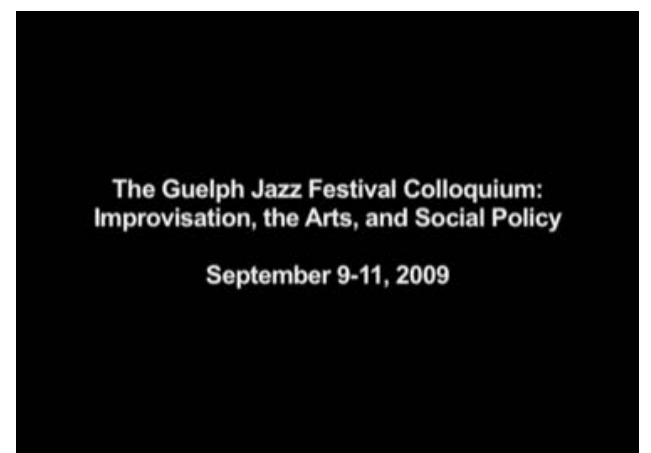

Click the image above to view a video of the "New Communities of Sound: Improvising Across Borders" workshop. [Adobe software may be required to view content.]

As a case in point, consider the "New Communities of Sound: Improvising Across Borders" workshop from the 2009 Guelph Jazz Festival Colloquium, cited by Fischlin et al. as an example of improvisation functioning "as a powerful bridge between musicians from . . . very different cultures" employing a "complex set of strategies that are working outside of and across known paradigms" (194). Without gainsaying the authors' representation of this event as a "boundary-shattering [act] of transculturation" (199-200) in which improvisation serves as a "model for understanding, and, indeed, for generating an ethics of cocreation" (198), an ethnographer carefully observing the dynamics of this staged encounter between African and North American artists might view it in a somewhat different light-as an uneasy oscillation between African diasporic grooves over 12/8 or 4/4 vamps that foreground the two Malian string players (and the reliably supportive drumming of Hamid Drake) and solo passages that highlight the predominantly North American wind players. Although Malian ngoni player Abdoulaye Koné does claim as much solo space as any of the latter, his solos-notwithstanding cosmopolitan interpolations reminiscent of psychedelic rock licks—often shift from free/rubato passages to vamp/groove sections. Indeed, he appears to initiate all but one of the vamp sequences, all of which end with Drake moving from strict timekeeping to more coloristic percussion. Drake's stylistic shifts not only highlight the conventional split between soloists and rhythm section players, but also foreground his key role as a culture broker here-with professional experience as a leading drummer both on the transatlantic improvised music scene and in the savannah-belt West African context of Foday Musa Suso's Mandingo Griot Society.

Surprisingly enough, in view of the manifest significance of such affiliations, the professional histories and prior relationships of the participating musicians receive relatively little consideration in FUN. While the authors' contention that "there was literally no common language between them" may be technically true (albeit with Canadian bilingualism covering most if not all of them), even a quick glance over their respective resumés undermines the notion that all the "relationships of communication that emerged" among them "did so solely on the basis of their improvised musicking" at this particular concert (Fischlin et al. 194). In fact, Ethiopian tenor saxophonist Getachew Mekuria had begun collaborating with Dutch guitarist Terrie Hessels some three years earlier in 2006, and Malian kamele ngoni player Jah Youssouf Camara had become socialized into the conventions of "World Free Jazz Funk" through collaborations beginning as early as 2004 with the Woodchoppers Association (a Toronto improvised-music collective), as had his countryman Koné during their 2009 summer tour of Canada. This same collective (which included FUN co-author Daniel Fischlin on twelve-string electric Hammertone) also provided a common frame of reference for Mexican soprano saxophonist Alain Derbez, who had performed-alongside Jah Youssouf-with its members in a 2007 Guelph Jazz Festival workshop entitled "Cross Border Conversations."

In short, previous intercultural experiences-also including soprano saxophonist Jane Bunnett's deep involvement with Afro-Cuban music and Mekuria's distinguished jazz career-had already stacked the deck in favor of collaborative "success" by ensuring that most participants had some familiarity with one or both default modes of improvisational interaction. Most musicians came to this workshop not just with distinctive and quite impressive improvisational talents to showcase, but also with a shared propensity for playing the role of culture broker-and for playing it on stage in front of paying audiences. Not surprisingly then, both North American guest artists, when interviewed by the festival's artistic director, affirmed that they had perceived an empowering link between their collaborative, intercultural improvisation and the progressive universalist ideals framing the event. Without disputing the sincerity of their views, critical ethnographic practice requires that the power relations among artists and organizers receive some degree of interrogation. Clearly, a group of experienced professionals hired to demonstrate for an audibly appreciative audience how intercultural improvisation "can potentially help us communicate across geographical and cultural differences" and "borders—both self- and externally-imposed—that might be holding communication in check" (Rob Wallace, qtd. in Fischlin et al. 195) ${ }^{7}$ could hardly be expected to question the effectiveness of that demonstration or the ideological premises motivating its staging. 
The foregoing analysis does not imply that this demonstration was in any way insincere, inauthentic, or ineffective merely by virtue of its staging (quite the contrary, in fact). ${ }^{8}$ Rather, it should underscore the critical recognition that collaborative modes of intercultural improvisation do not simply "promote a dynamic exchange of cultural forms, and ... encourage new socially responsive forms of community-building across national, cultural, and artistic boundaries" (Heble et al. 191), but also perform the enactment of those utopian goals, epitomizing the ideal of improvisation rooted in transatlantic Afrological practice.

This means that intercultural, collaborative improvisation must thus be understood as ritual performance-whether of individual expressive freedom or collective transcultural communitas-by artists who usually form their conceptions through prior observation of and participation in rehearsals, workshops, and concerts. The Guelph workshop artists did not spontaneously start "improvising across borders" with one another at a chance encounter on a street corner, nor did they forge "new communities of sound" upon meeting in a back-room jam session. Instead, the festival organizers gathered them together in the stylized informality of a workshop context—what Dean MacCannell might consider a "staged back region" (Tourist 99) — to present a well-crafted simulacrum of such a first-contact situation, with the full knowledge of all parties involved (including experienced audience members) that the artists had staked their professional reputations upon their ability to make this situation "work."

At the end of the day, I firmly believe that complicating a straightforward, affirmative reading of this event does not at all invalidate ICASP's investment in conceptualizing improvisation as a "model for political, cultural, and ethical dialogue and action," even if it does delimit its scope to the transatlantic free jazz traditions most prominently featured at the Guelph Jazz Festival. Rather, I would contend that a more nuanced perspective-such as that suggested by Rob Wallace in his opening remarks-reveals the nature and depth of that investment, and in so doing, brings to light otherwise obscure processes of constructing meaning around collaborative, cross-cultural exchanges.

\section{Sounds Provocative: The Politics of Improvisational Conflict}

When intercultural collaborations such as "New Communities of Sound" succeed in evoking the desired parallels between improvisational and utopian modes of musical and social interaction, the staging aimed at overdetermining this outcome tends not only to obscure the material power relations among the agents involved, but also to make an ideal performative realization seem natural and inevitable. But what happens when the artists on stage somehow fail to make the collaboration work as advertised? How might ethnography then approach the dystopian modes of musical interaction engendered by a willful refusal to conform to the "responsibility, interdependence, trust, and social obligation" necessary for improvised intercultural collaboration to function as a "model for understanding" (Fischlin et al. 198)? As the case of the trio concert of Sainkho Namtchylak, William Parker, and Hamid Drake at the 2004 Guelph Jazz Festival demonstrates, extemporaneous musical encounters that fail to measure up to the ideal of "democratic, humane, and emancipatory practice" can nonetheless reveal conflicts of concert production that question the cross-cultural applicability of this ICASP paradigm.

The division of labour between soloists and sidemen amidst the carefully staged egalitarianism of the "Communities of Sound" workshop provides an apt example of how the invisible hand of the music industry can sometimes trump the best intentions of organizers, artists, and audiences. In North America, transatlantic improvised music is typically presented as jazz-however avant-garde-thus ensuring that most performers have experience in code-switching between the utopian ideals of the former and the pragmatic conventions of the latter-including head-solo-head structures, 45-minute sets of 5-10-minute tunes, and traditional instrumental roles. In fact, quite a few of the most acclaimed groups (artistically as well as commercially) on the transatlantic scene work quite comfortably within the commercial structures of the "bebop business."

Analogous forms of code switching occur among world-music artists as well, albeit with the direction sometimes reversed. In the case of North Indian classical improvisation-which, as Fischlin and Heble have stipulated, does not embody the ideals of "antihegemonic resistance or critical strategies of alternative community building" (2)—Daniel Neuman's foundational research indicates that the deep social-structural hierarchy of vocal and instrumental soloists (artists) over melodic and rhythmic accompanists (artisans) once entailed a marked subordinate status for the latter, both on stage and off. Not only did accompanists rarely if ever share the spotlight, but their lower caste and prestige required them to settle for a small fraction of the remuneration granted to the soloists for whom they were also compelled to do backstage favors and errands. As Neuman observes, however, once soloists like Ravi Shankar began touring Europe and America, their accompanists soon learned that "audiences in the West [were] not sensitive to the differences in status and rank of soloist and accompanist," and so perceived them "as an equal (or near-equal) of the soloist" (Life of Music in North India 193). "From the point of view of foreign audiences, they were perceived as 
part of a duet" ("Social Organization of a Music Tradition" 241) and began to behave accordingly, upsetting traditional hierarchies and substantially raising their prestige and performance fees.

This example, together with the previous one, strongly suggests that the extent to which an improvisational performance embodies ICASP's "democratic, humane, and emancipatory" ideals may depend less upon its genre (idiomatic or non-idiomatic) than upon the boundary conditions of its specific context. From this standpoint, "successful" ICASP improvisations appear to require consensual alignment in favor of those ideals among organizers, artists, and audience members; conversely, the absence or breakdown of such consensus would likely result in "socalled failed improvisations" that "don't work in the model ways . . . they ought to" (Fischlin et al. 205). Fischlin, Heble, and Lipsitz represent the Namtchylak-Parker-Drake concert as a "particularly striking example" of "musical 'failure," one "so controversial, so challenging, so dramatic, and so extreme" that it apparently could still "provoke, and indeed insist on commentary" (206). Since any number of bloggers, critics, and scholars have already spilled a good deal of ink on the matter, I have no intention to involve myself here in debates about what really happened and should have happened; I seek rather to demonstrate what careful, ethnographic attention to the framing of both this event and the subsequent debate can reveal about the tensions, conflicts, and contradictions that arise from attempts to realize ISCAP's utopian ideals within a context where music industry relations of production and other adverse circumstances undermine consensus among backstage, onstage, and offstage agents.

As I was not present at the event, and am interested less in settling disputes over details than in analyzing the organizers' interpretation of what happened there, I will ground my inquiry in the "insider account" of events provided in FUN, insofar as it accords with eyewitness reports:

From the very opening notes of Namtchylak's performance . . . it became clear to festival organizers . . . that there was something seriously amiss. After singing a repeated, high-pitched, piercing [phrase] . . for about two minutes, Namtchylak looked at her watch and folded her arms, as if . . . in a deliberate gesture of defiance or protest ... After about forty minutes of the same [phrase] (with Parker and Drake trying their very best to save the performance by laying down some powerfully energetic grooves), festival organizers (who had met spontaneously in the wings of the hall to discuss the situation ...) made a difficult decision to interrupt the concert and ask Namtchylak what was wrong ... [A]fter airing her grievances, ultimately Namtchylak went to deliver a full . . . performance that revealed the wonders and intensity of her vocal range and the potency of her voice. (Fischlin et al. 211-12)

By all accounts, a significant portion of what audience remained at the time of the interruption vehemently and vocally objected to it, both while it was occurring and long thereafter in subsequent conversations, online-forum posts, and scholarly publications. Furthermore, most accounts, whether sympathetic to the organizers or to Namtchylak, also concur in their portrayals of Parker and Drake as exemplary in behaviour throughout: from the sustained intensity of their initial performance, through the silence they observed during the interruption, to their renewed and ultimately successful efforts to engage Namtchylak in an improvisational dialogue thereafter.

As an erstwhile concert organizer and ethnographer whose work often analyzes the behaviour of concert organizers (myself included), I can easily identify and empathize with the insiders' dilemma as sketched above, but must admit to being perplexed as to the timing and ostensible motivation of their intervention. Forty minutes into the trio's set-with the greater part of their performance likely already over, and any damage in alienating sponsors and audience members probably already done-strikes me as an odd moment to intervene, when it might certainly have been easier for the organizers just to let the performance clock itself out and move on. Why did they feel the need to engage Namtchylak publicly_and quite exceptionally_in order to "rectify the situation," and just what aspects of situation did they hope to set right?

In reflecting upon the controversy thus engendered, the authors acknowledge that "[t]he event, clearly, showed neither the Guelph Jazz Festival nor Sainkho Namtchylak at their best. The concert failed, by any standard, to live up to any claims that we, as authors, might like to make for the ability of improvised music-making to inculcate participatory virtues of engagement, dialogue, and tolerance, or to promote socially responsive forms of community building across cultural boundaries" (218). This assessment suggests a plausible motivation for the organizers' actions: namely that they regarded (and apparently still regard) Namtchylak's behaviour as an egregious breach, not merely of stage etiquette, professional norms, or contractual obligation, but also fundamentally of faith and commitment to the ideals that the performance was supposed to embody. In a chain of events closely following the script of symbolic anthropologist Victor Turner's model of "social drama" (see Dramas, Fields, and Metaphors (37-42), the organizers responded to this breach by initiating a crisis, followed by efforts at redress, culminating in an eventual reintegration (albeit one that clearly did not entirely resolve the issues raised). From this social-dramatic interpretative standpoint, the interruption of the performance would seem to represent a means of getting Namtchylak back into 
character, thus concluding the concert with a reaffirmation of the organizers' master narrative of intercultural dialogue and mutual understanding.

By refusing to perform in her designated, and presumably quite accustomed, role to "promote a dynamic exchange of cultural forms, and to encourage new socially responsive forms of community-building," ${ }^{\text {N10 }}$ Namtchylak shattered the performative frame through which the trio's improvisation would otherwise have become invested with the preferred meanings of ICASP's ideal-type, and in so doing, revealed it as a culturally specific form of improvisational practice with its own "idiomatic" conceptions, conventions, and values. In attempting to restore and recuperate these preferred meanings, the organizers_-inadvertently but quite manifestly_revealed their unmarked category as a construction of power and privilege, as Namtchylak pointedly observed in her apt (if perhaps solipsistic) remark, "what is freedom then?"

Of course, one might just as well question "whose freedom then?" and "what are its limits?" as indeed the insider authors of FUN do: "it's wrong, we believe, to assume that improvisation is in any simplistic way synonymous with freedom from the responsibility of cocreative interplay" (215-16). In building up to the argument that "there needs to be a more nuanced understanding of (limits to) personal expression as a function of multiple intersecting levels of responsibility and reciprocity that make the ethics of cocreative community possible" (216), they identify as the gravamen of their dispute with Namtchylak her alleged enactment of conventional, hierarchical, leader-sidemen relations on stage that clashed with their idealistic framing of an egalitarian intercultural exchange:

Namtchylak's dogged unresponsiveness to the other players onstage during her Guelph performance might well be heard as a refusal to be part of the total ensemble, a refusal to participate in dialogue or even try to resolve differences (musical or otherwise) ... Namtchylak seemed to be very much center stage that evening: the show foregrounded her self-interest and authority, this despite the considerable efforts and contributions of her bandmates onstage. (214)

In short, this account would suggest that Namtchylak's refusal to play the foreign other whose difference could be bridged through egalitarian intercultural improvisation, and the intervention it occasioned, revealed the stark politicaleconomic relations of production that the festival had worked so hard to conceal: not only the onstage leader/sidemen division of labour, but also (more problematically if the continuing controversy is any indication) the backstage employer/employee balance of power. From this standpoint, the organizers' intervention was not so much to help find out "what was wrong" as to try to "rectify the situation" (212): by escalating the social drama from breach to crisis, they sought to reintegrate Namtchylak into their communities of artists and listeners united in common commitment to a narrative of intercultural understanding through improvisation.

\section{The Other Side of Here \& Now: Cross-Cultural Reflections on Intercultural Improvisation}

The complex politics of artist-organizer power relations in intercultural improvisational performances mirrors the equally complex semiotics of artist-audience meaning production at such events. In my own research on the Vision Festival, I argue that one of the main modes by which artists and audiences collaboratively produce meaning is fundamentally dramaturgical in nature:

In the course of performance, avant-garde jazz artists construct and project unique musical personalities . . . transformed and transcended as necessary to meet the challenging contingencies of the moment. Improvising musicians interact with one another onstage on the basis of these projected personae ... Knowledgeable audience members may attribute personalities to the improvisers . . . and perhaps even recognize and identify with the glimpses of radical potentiality provided by the extemporaneous construction of self. Thus improvisers present themselves to each other, as well as to the audience, in dramatic performances of their musically constructed selves and interrelationships: each one the co-author of a liminal play of meanings. ("Scenes, Personae and Meaning" 49)

As the foregoing discussion of intercultural improvisation should illustrate, however, the script for this semiotic play is written only in part according to a contingent balance or prevailing consensus among artists and audience members, the rest dictated by master narratives reflecting socio-economic relations of cultural production and consumption.

This critical engagement with the social-structural dimensions of meaning production represents one of the main areas in which ethnomusicology can contribute to improvisation studies. From anthropological conceptualizations of cultural performance to sociological notions of framing and ideal-types, contemporary music ethnography can add depth and nuance to analyses of how contextually specific meanings are constructed in, through, and around 
improvisational interaction, particularly in cases of intercultural collaboration. An empirical focus on musical concepts, behaviors, backgrounds, and sounds can provide unique insight into the dynamic balance between structure and agency in staged events premised upon establishing improvisational dialogue across geographic and cultural barriers.

From an ethnographic perspective, one key challenge to broadening the scope of the ICASP paradigm arises from its construction of an unmarked ideal-type (improvisation) around a culturally specific set of transatlantic Afrological practices, which then serves as a standard against which other global forms of extemporaneous music-making might appear more or less accomplished, achieved, or fully realized. Improvisation encompasses a wide range of practices worldwide, and aligning any of these with struggles for social justice depends not on generic formal characteristics of musical processes and products, but rather upon a contingent articulation of culturally-specific meanings by artists, professionals, and audience members invested in certain compelling narratives that structure musical experience in relation to their own needs for agency and empowerment. When various participants view the same musical practices as invested with different culturally specific meanings, any overarching narrative must be understood as a staged enactment of a shared ideal performed to evoke, represent, or symbolize a common theme (e.g. "new socially responsive forms of community-building across national, cultural, and artistic boundaries").

In this regard, ethnomusicological concerns for reflexivity, especially the explicit recognition of how scholarly research paradigms shape the meanings of cultural practices under study, cannot but foreground how ICASP's own axiological commitments to "democratic, humane, and emancipatory" music making in cosmopolitan transatlantic contexts shape its interpretive perspective and semiotic impact on improvisational practices worldwide. In particular, the reflexive selfconsciousness ethnographers seek to cultivate can reveal the extent to which ICASP's engaged research praxis of staging events it then studies may overdetermine musical outcomes and assessments of their significance, especially in cases of intercultural improvisation where master narratives steer musical interaction in preferred, progressive directions. By the same token, insofar as all scholarly investigations represent socio-cultural interventions of one sort or another, ICASP's candor in highlighting its own activist convictions provides an inspiring model for ethnomusicologists and other researchers who share them. Ultimately, in offering improvisation studies an empirical, self-critical standpoint to temper its affirmative claims to the liberatory connotations of improvisation, ethnomusicologists stand to benefit from the verve and vitality of an emergent field with transformational ambitions well beyond the scope of their interdisciplinary and increasingly engagement-oriented inclinations.

\section{Notes}

${ }^{1}$ George Lewis's work maps out some of the concerns in this regard: see, for example, his critique ("Gittin' To Know Y'all" 22-23) of Derek Bailey's problematic "idiomatic"/"non-idiomatic" distinction (Musical Improvisation 4-5, 151) and of similar claims of "genre transcendence" (Lewis, "Afterword" 166), as well as his application ("Improvised Music after 1950" 140) of John Fiske's notion of "exnomination" (Media Matters 42) to improvisatory traditions. For linguistic, anthropological, and feminist perspectives on the inherent power dynamics of marking and unmarking, see Howard Greenberg ("Research on Language Universals"), Mary Bucholtz and Kira Hall ("Language and Identity"), and Donna Haraway ("Situated Knowledges").

${ }^{2}$ While I use transatlantic here to denote the ongoing circulation of these traditions between various metropolitan scenes of North America and Europe-a process clearly fundamental to maintaining the mutual intelligibility of improvisational practices_- also mean to connote Paul Gilroy's notion of the Black Atlantic as defining, through displacement, the locus of dispersed yet dialogically interconnected sites for the development of African diasporic cultural hybridity. Although space constraints preclude further exploration of the latter metaphor's implications, its roots in the triangle trade of slavery cannot but evoke the southern Atlantic regions of Africa, Latin America, and the Caribbean, often marginalized or excluded in discourses of "improvised music"-an exclusion starkly foregrounded by the characterization (pragmatically necessary, if theoretically troublesome) of collaborations between North and South Atlantic improvisers as "intercultural."

${ }^{3}$ ICASP researcher Alan Stanbridge's critique of such allegorical understandings ("From the Margins to the Mainstream" 7-11) with respect to the work of Jacques Attali (Noise 20,133-148) offers a useful precedent.

${ }^{4}$ As it happens, Max Weber formulated his notion of ideal-type, "a purely ideal limiting concept with which the real situation or action is compared and surveyed for the explication of certain of its significant components," in rather ICASP-compatible terms as a construct that "in itself is like a utopia which has been arrived at by the analytical accentuation of certain elements of reality" (Methodology of Social Sciences 93, 90). 
${ }^{5}$ See lan Carr's (1971) story—quoted in Jost (Free Jazz 8) and cited by Rinzler (Contradictions of Jazz 62) about a saxophonist blackballed from a "free" jazz session for playing an old British music-hall tune throughout the encounter. Rinzler brings to light some significant implications of this anecdote in his consideration of the maxim "You can play anything, but you can't play just anything" (116).

${ }^{6}$ Some scholars of intercultural improvisation, notably Jason Stanyek in his analysis of Dizzy Gillespie and Chano Pozo's collaboration "Manteca" (featuring incommensurably clashing jazz and Latin rhythms due to the lack of a common measure between superimposed swing and straight subdivisions of the beat), have offered affirmative readings of such dissonant encounters as "coexistence and maintenance of diverse sonic and personal identities" through the "construction of communicative spaces in which divergent identities can be performed and articulated" (116). Nonetheless, I doubt that Stanyek would ever dismiss Charlie Parker's collaborations with Machito's AfroCubans_-including "Mango Mangue" and Chico O'Farrell's Afro-Cuban Jazz Suite-as "industrial intercultural collaborations' which tend to iron out difference to create what might be thought of as neutered hybrids" (116) just because Parker employed an innovative double-time conception that allowed him to mesh seamlessly with Machito's rhythm section. From an ethnomusicological perspective, musical discrepancies characteristic of first-contact encounters may resolve via either code-switching bimusicality (embodied by Mario Bauzá, music director of Machito's band and alumnus of both Cab Calloway's Cotton Club Orchestra and Chick Webb's Savoy Orchestra) or individual feats (like Parker's) of empathetic engagement that produce satisfaction and pride on both sides.

${ }^{7}$ Although omitted in the quotation printed in FUN, the reservations Rob Wallace included in his introductory talk, before the workshop he facilitated and performed in, suggest some degree of discomfort with the ICASP agenda: "These workshops in some senses are kind of controversial, maybe sort of in the background or behind the scenes, because improvising across borders in this case implies some paradoxes, perhaps: one, that improvisation might be in some sense a kind of universal musical language . . . that can potentially help us to communicate across geographical and cultural barriers and differences; but also, two, that there are borders set up in the first place, both self and externally imposed borders that might be holding that kind of communication in check. And that casts some doubt onto the notion of some sort of universality of improvisation or any other kind of humanistic endeavor, like democracy or human rights or name the term" (my transcription from video [passages omitted from FUN are set in italics for emphasis], 4:00).

${ }^{8}$ As Heble's follow-up interviews with Bunnett, Derbez, and Wallace illustrate (Heble et al. 201-02), artists staging intercultural performances of this sort can demonstrate not only a self-conscious understanding of the allegorical meanings of their collaborative improvisations, but may also consider them fundamental to their aesthetic practice.

${ }^{9}$ One all-star quartet that headlined regularly at the Vision Festival for many years rarely strayed from the abovenoted jazz conventions, especially the hierarchy between a charismatic leader (who no longer worked as a sideman) and supportive sidemen (all of whom also led their own groups). In a private interview, one band member expressed satisfaction with the expressive opportunities available to him in the group, but noted that "when [the leader] picks up his [instrument], your solo is finished." Nevertheless, context matters: when I asked that same leader why he had one year at Visionfest veered from his accustomed set list into a completely free-improvisational marathon performance, he replied that, in the unique circumstances of that festival, he believed people would respond well to it.

${ }^{10}$ By 2004, Namtchylak had well over a decade of experience on the transatlantic, intercultural improvisation scene, and had just toured Europe with Parker and Drake.

\section{Works Cited}

Attali, Jacques. Noise: The Political Economy of Music. Translated by Brian Massumi, U of Minnesota P, 1985.

Bailey, Derek. Musical Improvisation: Its Nature and Practice in Music. Prentice-Hall, 1980.

Bucholtz, Mary and Kira Hall. "Language and Identity." Companion to Linguistic Anthropology, edited by Allessadro Duranti, Blackwell, 2004, pp. 369-394.

Carr, Ian. "Freedom and Fish Soup." Melody Maker, vol. 22, May 1971, p. 41.

Charry, Eric. Mande Music: Traditional and Modern Music of the Maninka and Mandinka of Western Africa. U of Chicago P, 2000. 
Chernoff, John. African Rhythm and African Sensibility: Aesthetics and Social Action in African Musical Idioms. U of Chicago P, 1979.

Currie, Scott. "The Revolution Never Ended': Cultural Politics of a Creative-Music Collective in New York City.” Jazz Research Journal, Special Issue: Jazz Collectives-Concepts and Contexts, vol. 5, no. 1-2, 2012, pp. 43-65.

---. "Scenes, Personae, and Meaning: Symbolic Interactionist Semiotics of Jazz Improvisation." Studies in Symbolic Interaction, vol. 42, 2014, pp. 37-50.

Fischlin, Daniel, and Ajay Heble. "The Other Side of Nowhere: Jazz, Improvisation, and Communities in Dialogue." The Other Side of Nowhere: Jazz, Improvisation, and Communities in Dialogue, edited by Daniel Fischlin and Ajay Heble, Wesleyan UP, 2004, pp. 1-42.

Fischlin, Daniel, Ajay Heble, and George Lipsitz. The Fierce Urgency of Now: Improvisation, Rights, and the Ethics of Cocreation. Duke UP, 2013.

Fiske, John. Media Matters: Everyday Culture and Political Change. U of Minnesota P, 1994.

Gilroy, Paul. The Black Atlantic: Modernity and Double Consciousness. Harvard UP, 1993.

Greenberg, Howard. "Research on Language Universals.” Annual Review of Anthropology, vol. 4, 1975, pp. 75-94.

Haraway, Donna. "Situated Knowledges: The Science Question in Feminism and the Privilege of Partial Perspective." Feminist Studies, vol. 14, no. 3, Autumn 1988, pp. 575-599.

Heble, Ajay. "About ICASP." Improvisation, Community, and Social Practice, www.improvcommunity.ca/about. Accessed 22 September 2014.

Jost, Ekkehard. Free Jazz. Da Capo, 1994.

Lewis, George E. "Improvised Music after 1950: Afrological and Eurological Perspectives." The Other Side of Nowhere: Jazz, Improvisation, and Communities in Dialogue, edited by Daniel Fischlin and Ajay Heble, Wesleyan UP, 2004, pp. 131-62.

---. "Afterword to 'Improvised Music after 1950': The Changing Same.” The Other Side of Nowhere: Jazz, Improvisation, and Communities in Dialogue, edited by Daniel Fischlin and Ajay Heble, Wesleyan UP, 2004, pp. 163-172.

---. "Gittin' To Know Y'all: Improvised Music, Interculturalism, and the Racial Imagination." Critical Studies in Improvisation, vol. 1, no. 1, 2004, www.criticalimprov.com/article/view/6.

MacCannell, Dean. The Tourist: A New Theory of the Leisure Class. Schoken, 1989.

Monson, Ingrid. Freedom Sounds: Civil Rights Call Out to Jazz and Africa. Oxford UP, 2007.

Nettl, Bruno. "Thoughts on Improvisation, a Comparative Approach.” Musical Quarterly, vol. 60, 1974, pp. 1-19.

---. "Introduction: An Art Neglected in Scholarship." In the Course of Performance: Studies in the World of Musical Improvisation, edited by Bruno Nettl and Melinda Russell, U of Chicago P, 1998, pp. 1-23.

Neuman, Daniel M. "The Social Organization of a Music Tradition: Hereditary Specialists in North India." Ethnomusicology, vol. 21, no. 2, May 1977, pp. 233-245.

---. The Life of Music in North India: The Organization of an Artistic Tradition. Wayne State UP, 1980.

Rinzler, Paul. The Contradictions of Jazz. Scarecrow, 2008. 
Stanbridge, Alan. "From the Margins to the Mainstream: Jazz, Social Relations, and Discourses of Value." Critical Studies in Improvisation, vol. 4, no. 1, 2008, www.criticalimprov.com/article/view/361.

Stanyek, Jason. "Transmissions of an Interculture: Pan-African Jazz and Intercultural Improvisation." The Other Side of Nowhere: Jazz, Improvisation, and Communities in Dialogue, edited by Daniel Fischlin and Ajay Heble, Wesleyan UP, 2004, pp. 87-130.

Turner, Victor. Dramas, Fields, and Metaphors: Symbolic Action in Human Society. Cornell UP, 1974.

Wallace, Rob, et al. "New Communities of Sound: Improvising Across Borders." Improvisation, Community, and Social Practice, 11 Sept. 2009, www.improvcommunity.ca/research/workshop-new-communities-soundimprovising-across-borders.

Weber, Max. Methodology of Social Sciences. 1949. Translated by Edward A. Shils and Henry A. Finch, Transaction, 2011. 